
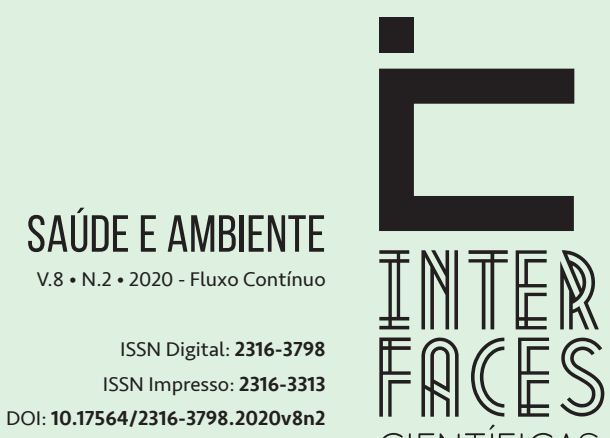

CIENTÍFICAS

\section{REFLEXÕES SOBRE VIOLÊNCIA DOMÉSTICA, COVID-19 E SAÚDE}

REFLECTIONS ON DOMESTIC VIOLENCE, COVID-19 AND HEALTH

REFLEXIONES SOBRE VIOLENCIA DOMÉSTICA, COVID-19 Y SALUD

Gustavo Henrique Franciscato Garcia ${ }^{1}$

Caroline Urias Challouts ${ }^{2}$

Marcelo Picinin Bernucci ${ }^{3}$ Hélio Sochodolak ${ }^{4}$

Tânia Maria Gomes da Silva ${ }^{5}$

\section{RESUMO}

A violência doméstica contra as mulheres é um dos mais sérios problemas contemporâneos. Cerca de $35 \%$ das mulheres no mundo são vítimas de violência doméstica, a maioria provocada por seus parceiros íntimos. Trata-se de um fenômeno que ocorre em países desenvolvidos e em desenvolvimento, embora a incidência seja maior nos países mais pobres. A Organização Mundial da Saúde afirma que a violência é causa de adoecimento físico e psíquico. Em 2006, no Brasil, a Política Nacional de Promoção da Saúde, enfatizou gênero como determinante social do processo saúde/doença e propôs a cultura da paz e dos direitos humanos para a construção de uma sociedade saudável. 0 objetivo desse artigo é apresentar reflexões sobre o impacto da violência na saúde das mulheres. Trata-se de um tema relevante nesses dias em que o isolamento social proposto pela OMS para conter a pandemia do Covid-19 evidenciou a vulnerabilidade das mulheres em seus próprios domicílios e deu prova da incivilidade do mundo.

\section{PALAVRAS-CHAVE}

Saúde da mulher; Direitos Humanos; COVID-19; Política Nacional de Promoção da Saúde. 


\section{ABSTRACT}

Domestic violence against women is one of the most serious contemporary problems. Around $35 \%$ of women in the world are victims of domestic violence, the majority caused by their intimate partners. It is a phenomenon that occurs in developed and developing countries, although the incidence is higher in low-income countries. The World Health Organization (WHO) states that violence is a cause of physical and psychological illness. In 2006, in Brazil, the National Health Promotion Policy was launched, which emphasized gender as a social determinant of the health / disease process and proposed a culture of peace and human rights for the construction of a healthy society. The purpose of this article is to highlight the risks of violence to women's health. It is a relevant topic in those days when the social isolation proposed by the WHO to contain the COVID-19 pandemic highligheted the vulnerability of women in their own homes and proved the world's incivility.

\section{KEYWORDS}

Women's health; Human Rights; Social Isolation; COVID-19; National Health Promotion Policy.

\section{RESUMEN}

La violencia doméstica contra las mujeres es uno de los problemas contemporáneos más graves. Alrededor del $35 \%$ de las mujeres en el mundo son víctimas de violencia doméstica, la mayoría causada por sus parejas íntimas. Es un fenómeno que ocurre en países desarrollados y en desarrollo, aunque la incidencia es mayor en los países más pobres. La Organización Mundial de la Salud afirma que la violencia es una causa de enfermedad física y psicológica. En 2006, en Brasil, la Política Nacional de Promoción de la Salud enfatizó el género como un determinante social del proceso de salud / enfermedad y propuso una cultura de paz y derechos humanos para la construcción de una sociedad saludable. El propósito de este artículo es presentar reflexiones sobre el impacto de la violencia en la salud de las mujeres. Es un tema relevante en aquellos días en que el aislamiento social propuesto por la OMS para contener la pandemia de Covid-19 destacó la vulnerabilidad de las mujeres en sus propios hogares y demostró la incivilidad del mundo.

\section{PALABRAS CLAVE}

Salud de la Mujer; Derechos Humanos; COVID-19; Política Nacional de Promoción de la Salud 


\section{INTRODUÇ̃̃̃o}

Violência é um conceito polissêmico de difícil apreensão, variável em distintas temporalidades e culturas. Contemporaneamente, é definida como o uso intencional de força física ou de poder contra si mesmo, contra outra pessoa, contra um grupo ou comunidade, que resulte ou que tenha probabilidade de resultar em ferimento, morte, dano psicológico, mau desenvolvimento ou privação (WHO, 2013).

Há práticas que nunca desparecem na história e a violência é um exemplo, constituindo-se em um fenômeno sócio-histórico, consequência de estruturas de sociabilidade que têm a forma e o conteúdo das expressões da história da formação de um país, de um estado, de uma cidade ou comunidade, manifestando-se na cultura das instituições, nas relações e nas subjetividades (MINAYO; SCHENKER, 2018). Entre as formas de violência, encontra-se a violência contra as mulheres ou violência de gênero.

Nas últimas quatro décadas, pelo menos, a violência contra as mulheres tem sido analisada, tomando como suporte teórico os estudos de gênero. Na perspectiva de gênero, a construção das subjetividades femininas é o resultado de um modelo cultural e histórico que constrói e legitima hierarquias entre os sexos. Para Scott (1995), gênero é uma forma primária de dar significado às relações de poder e contribui para desconstruir o essencialismos e binarismos sexuais.

Portanto, se as considerações de Scott (1995) permitem pensar que os sujeitos são formados por meio de dispositivos sociais que lhes atribuem determinadas características, materializando-as em seus corpos, a violência pode ser pensada como resultado de um processo histórico que construiu masculinidades opressoras em contraposição a feminilidades subalternas, legitimando as estruturas de dominação.

Este artigo, de abordagem teórica e reflexiva, objetiva refletir sobre a violência doméstica contra as mulheres e seus impactos sobre a saúde. Trata-se de um tema importante, notadamente em períodos de excepcionalidade, como na situação de pandemia da COVID-19. Embora muito já se tenha falado sobre a violência, constata-se a importância de ampliar os estudos acerca das consequências sobre a saúde das vítimas.

\section{VIOLEENCIA E GÊNERO}

Sabe-se, pelas estatísticas, que os homens são as principais vítimas de mortes por causas externas, a exemplo dos acidentes de trânsito ou com armas de fogo. Já a violência contra as mulheres é marcada pela invisibilidade, uma vez que a grande parte dessas ocorrências se dão no âmbito privado, não geram atendimento e terminam subnotificadas (GARCIA, 2016).

Globalmente, cerca de 35\% das mulheres sofrem violência e grande parte transcorre no ambiente doméstico, praticada pelos parceiros ou ex-parceiros, muitas vezes com desfecho fatal. Estima-se que, em todo o mundo, 60 mil mulheres sejam mortas anualmente por feminicídio (WHO, 2013).

O Brasil se classifica em quinto lugar numa lista de 83 países onde mais ocorrem feminicídios (taxa de 4.8 feminicídios para cada 100 mil mulheres) e somente e 2017 mais de 221 mil mulheres 
fizeram registros de lesão corporal dolosa, uma média de 606 casos/dia. Mulheres negras foram as mais agredidas (IPEA, 2019).

As pesquisadoras Neme e Sobral (2019), que integraram um estudo realizado pelo Fórum Brasileiro de Segurança Pública e Instituto Datafolha, informam que, em 2019, quase 60\% da população brasileira, sem diferença expressiva entre homens e mulheres, afirmou ter visto um ato de violência contra as mulheres em seu bairro ou comunidade; em 2017 eram 7 pontos percentuais a mais. Contudo, essa redução, segundo as pesquisadoras, não corrobora com as informações femininas, pois $27,4 \%$ das mulheres afirmaram ter sofrido alguma forma de violência nos últimos doze meses, basicamente a mesma prevalência verificada em 2017 (28,6\%). Observou-se que a violência atinge mais as mulheres negras $(13,3 \%)$ do que as brancas (6,5\%).

Os maridos, companheiros e namorados ou ex-parceiros foram os principais agressores (23,8\%), mas mulheres foram também agredidas pelos vizinhos (21\%) e pelos ex-cônjuges, ex-companheiros ou ex-namorados (15,2\%). Violência verbal (28\%), violência física (16,5\%) e ameaça de agressão (22, 5\%) foram as formas mais prevalentes; sendo o domicílio $(42 \%)$ e a rua $(29,1 \%)$ os locais de maior perigo (NEME, SOBRAL, 2019).

A violência é um fenômeno multicausal. A Organização Mundial da Saúde (OMS, 2002) recomenda que sua análise leve em conta fatores biológicos, econômicos, políticos e ecológicos, dando ênfase à normas culturais que justifica a violência que, no caso das mulheres, tem íntima relação com o machismo.

Na perspectiva do modelo ecológico, considera-se que, no Brasil, a organização familiar patriarcal sustentou um sistema de opressão de gênero que vigorou desde os primeiros séculos da colonização. A quem mais, senão ao patriarcado e seus congêneres, responsabilizar pela exclusão das mulheres das esferas de poder político, dos espaços de liderança nas grandes empresas nacionais e transnacionais, da injusta desigualdade salarial por gênero, na divisão sexual do trabalho? Falar em patriarcado nos dias de hoje parece obsoleto, porque as pessoas tendem a associá-lo tão somente às sociedades tradicionais, na figura do pater famílias do direito romano, que é efetivamente a base das legislações modernas, mas a verdade é que a despeito das mudanças socioculturais sua dinâmica segue firme na contemporaneidade (BARSTED, 2016).

Desde os anos 1960, o Movimento Feminista fez da luta contra a violência uma de suas principais bandeiras. $O$ enfrentamento da violência na atualidade se ampliou com a interseção de gênero a outros marcadores identitários, notadamente raça e classe. Busca-se resgatar uma dívida histórica do feminismo que, na sua gênese, deu pouca atenção às demandas das mulheres fora do eixo Europa-Estados Unidos. A interseccionalidade é a força do feminismo contemporâneo (HOOKS, 2019).

Hooks (2019) acusa que a desconstrução dos processos eurocêntricos de relações de poder impostos pela lógica europeia foi vitoriosa ao denunciar a exploração dos homens, mas fez vistas grossas às opressões raciais de gênero. Nesse aspecto, tem sido vitoriosa a emergência das lutas reivindicatórias plurais por direitos no interior do movimento feminista, em uma espécie de endofagia em que mulheres negras, lésbicas, indígenas, ribeirinhas, trans, moradoras de regiões da periferia do capitalismo, trabalhadoras do sexo, entre outras denunciam, em uma polifonia de vozes, o silenciamento a que estiveram submetidas não apenas pelos homens, mas também por outras mulheres, desmistificando uma suposta sororidade feminina, afirma a autora citada acima. 
Atualmente, a luta contra a violência segue sendo uma das principais bandeiras das mulheres, pois ainda não se pode comemorar a equidade de gênero e a paz social. É o que se depreende das notícias relacionadas ao aumento da violência doméstica durante a pandemia do coronavírus.

\section{VIOLÊNCIA DE GÊNERO EM TEMPOS DE COVID-19}

O primeiro caso da COVID-19 foi confirmado na cidade de Wuhan, província de Hubei, na República Popular da China, em dezembro de 2019. Devido à rápida disseminação da doença, em 11 de março de 2020, a OMS declarou o surto da epidemia e orientou os países que isolassem os casos suspeitos e iniciassem isolamento social; estratégias tidas como fundamentais para conter o aumento dos casos da doença e a sobrecarga de serviços de saúde (MARQUES et al., 2020; OPAS, 2020).

É a sexta vez na história que uma emergência de saúde pública internacional foi declarada. As anteriores foram: H1N1 (2009); poliovírus (2014), ebola na África Ocidental (2014), Zika (2016) e ebola no Congo (2018). Globalmente, até o dia 11 de junho de 2020, 7.723 .958 casos de COVID-19 e 413.372 mortes haviam sido notificadas (OPAS, 2020). No Brasil, até o dia 8 de junho de 2020, as Secretarias Estaduais de Saúde confirmaram 694.116 casos, com 36.602 mortes (G1, 2020).

0 isolamento social, caracterizado pela redução do contato entre as pessoas, com restrição de viagem, escola, trabalho e comunicação social, visando aplacar o máximo possível a incidência do vírus e reduzir o número de infectados tem alterado de maneira substancial a rotina das famílias. A intensa convivência entre os casais fez disparar os índices de violência doméstica como um rastilho de pólvora: China, Estados Unidos, Reino Unido, Alemanha, França, Espanha, Itália, Austrália, Canadá, Singapura, Chipre, Peru, Argentina, Colômbia Brasil etc. (MARQUES et al., 2020; VIEIRA et al., 2020).

No Brasil, houve aumento nos registros de violência doméstica desde os primeiros finais de semana após os governos estaduais decretarem o distanciamento social: $50 \%$ no Rio de Janeiro e $15 \%$ no Paraná. Foram notificados aumentos de casos de violência doméstica contra mulheres também no Ceará, Pernambuco e São Paulo e, na maior parte das vezes, as agressões envolveram também as crianças e as adolescentes (MARQUES et al., 2020). Entre os dias $1^{\circ}$ a 25 de março os principais canais de atendimento a mulheres em situação de violência, o Disque 100 e o Ligue 180, receberam 18\% mais ligações de denúncias (VIEIRA et al., 2020).

Segundo o Fórum Brasileiro de Segurança Pública, com a consolidação da quarentena, caiu o número de pedidos de medida protetiva de urgência em todos os estados, porque essa é uma medida que só pode ser solicitada presencialmente, mas, em contrapartida, entre fevereiro e abril de 2020, os relatos de violência doméstica no Twitter aumentaram $431 \%$ e $67 \%$ delas foram feitas por mulheres.

A instabilidade econômica e o medo da doença geram maior nível de estresse e tensionam as relações. Assim, o domicílio, entendido como lócus de proteção e amparo para as mulheres têm demonstrado ser, ao invés disso, um lugar de perigo. Considere-se, ainda, o agravante de que o acesso às redes de proteção socio-humanas, como parentes e amigos, sociotécnicas e institucionais, como as Delegacias de Mulheres estão mais difíceis (VIEIRA et al., 2020). 
Para Marques e colaboradores (2020), se a redução do contato social da mulher vítima de violência com amigos e familiares é um problema, também a convivência prolongada de famílias de baixa renda aglomeradas em residências pequenas é um fator de tensão nesses tempos de isolamento (MARQUES et al., 2020).

Talvez ainda seja demasiado cedo para a discussão dos números da violência durante a pandemia. A análise merece atenção especial quanto à localização geográfica da mulher, visto que os diferentes países apresentam números distintos, e também quanto ao período, com a situação, tendendo a se tornar menos dramática à medida que a doença vai perdendo força em alguns países, que mais serviços de proteção vão sendo criados e que mais e mais mulheres conseguem tomar conhecimento dos meios de acesso a esses serviços. Ressalte-se, no entanto, que a pandemia da COVID-19 não pode ser responsabilizada pela violência doméstica contra as mulheres. Ela tão somente jogou luzes sobre um problema que se encontra desde há muito inscrito nas estruturas das relações sociais de gênero em diferentes culturas ao redor do mundo.

\section{VIOLÊNCIA DE GÊNERO E ADOECIMENTO}

Saúde e doença são processos sociais e históricos. Desde a década de 1960 esse debate vem sendo realizado numa perspectiva abrangente, com a substituição do paradigma biomédico pelo biopsicossocial. 0 modelo biomédico entende a doença como um desvio de variáveis biológicas em relação à norma. Essa visão mecanicista dificultou a compreensão dos impactos da violência sobre a saúde das vítimas. No modelo biopsicossocial, ao contrário, a saúde é inseparável das condições concretas da vida (MINAYO; SCHENKER, 2018).

A proposição de saúde como um direito de todos e um dever do Estado foi trazida pela Constituição de 1988, que defendeu a igualdade de todos, não apenas em relação à saúde, mas também a todas as esferas da vida, incluindo as relações de gênero. Essa Constituição resultou de um contínuo de lutas no âmbito nacional e internacional, que vão das sufragistas, no século XIX, à Convenção para a Eliminação de Todas as Formas de Discriminação contra a Mulher (CEDAW), à criação do SOS Mulher e das Delegacias Especializadas no atendimento às Mulheres (DEAMs), além de movimentos como "Quem ama não mata”, "O pessoal é político" e "Nosso corpo nos pertence” (BARSTED, 2016).

Desde o final da década de 1990, a OMS (2002) reconheceu o alto potencial da violência para provocar adoecimento. As condições concretas de vida foram entendidas como podendo ter mais impacto sobre a saúde do que fatores biológicos. Entre os agravos físicos associados à violência contra as mulheres, segundo a OMS, estão: dor crônica, lacerações, escoriações, queimaduras, lesões abdominais e torácicas, diarreias e mau funcionamento do intestino, úlceras, gastrites ou refluxos esofágicos, fibromialgias, danos oculares e alterações no peso.

Em termos de saúde sexual e reprodutiva, há relatos de fluxo vaginal persistente, aborto espontâneo, sangramento genital, doenças inflamatórias da pélvis, infertilidade, retardo no desenvolvimento intrauterino, aborto, morte materna, partos prematuros. Identificou também relação entre violência e depressão, ansiedade e fobias, com aumento nos riscos de suicídio. Mulheres que sofrem violência 
também se encontram mais vulneráveis ao HIV/DST; devido à dificuldade de negociar sexo seguro com companheiros violentos (OMS, 2002).

A Organização Mundial da Saúde (WHO 2013) reconhece ainda associação entre transtorno mental e incapacidade psicossocial em mulheres vítimas de violência, com aumento de incidência de depressão e de ansiedade; anorexia nervosa, transtorno de estresse pós-traumático. Assim, a violência é um estressor psicossocial capaz de gerar alterações fisiológicas de amplos efeitos sobre a saúde, ainda que se admita que algumas mulheres consigam dar respostas menos traumáticas.

Mulheres vítimas de violência têm menor percepção do seu estado de saúde comparado àquelas não agredidas, costumam ir mais aos médicos, apresentam queixas vagas, dores imprecisas e sem correspondência a patologias conhecidas. Como consequência, passam a ser tratadas como problemáticas e nervosas. Por essa razão, é importante que os profissionais da atenção primária identifiquem a violência (BATISTA et al. 2018). Como nem sempre as mulheres se sentem confortáveis e seguras para expor a violência que sofrem dos parceiros, o entendimento do profissional da saúde acerca da violência de gênero, livre de preconceitos e estereótipos, é muito importante.

\section{ENFRENTAMENTO DA VIOLÊNCIA E PROMOÇÃO DA SAÚDE}

Uma das principais contribuições para um novo pensamento sobre o processo de saúde e doença foi a introdução do conceito de promoção da saúde. Entende-se a promoção da saúde como estratégias e formas de produzir saúde no âmbito individual e coletivo, visando atender às necessidades sociais de saúde e garantir melhores condições de vida para a população (MINAYO; SCHENKER, 2018). Trata-se, de uma proposta de política pública mundial, aprovada na Primeira Conferência Internacional de Promoção da Saúde, ocorrida em 1986, no Canadá, onde se consolidou que o tema da saúde é social e está diretamente relacionado à forma de sociedade e de Estado. Nas conferências subsequentes foram incorporados os determinantes sociais da saúde e diminuída a ênfase em intervenções behavioristas (BUSS, 2000).

Seguindo Minayo e Schenker (2018), somos informados que, no Brasil, entre as medidas de contenção da violência, merecem destaque a promulgação pelo Ministério da Saúde, da Política Nacional de Redução da Morbimortalidade por Acidentes e Violência (PNRMAV), em 2001. A PNRMAV distinguiu acidente (não intencional) e violência (intencional) e a primeira iniciativa foi um programa com foco na assistência às vítimas, dando ensejo ao Serviço de Atendimento Móvel de Urgência, o Serviço de Atendimento Móvel de Urgência (SAMU). Algumas ações subsequentes foram tomadas visando melhorar a notificação de mortes e agravos, entre elas, a introdução do tema da violência nas rotinas de serviços e a notificação de casos de violência, envolvendo crianças, adolescentes, mulheres e outros grupos vulneráveis, informam os pesquisadores, ainda segundo a autora e seus colaboradores (MINAYO; SCHENKER, 2018).

Outra medida importante se deu em 2004, quando da instituição da Rede Nacional de Prevenção da Violência e Promoção da Saúde em estados e municípios, fortalecida em 2006 com a implantação da Política Nacional de Promoção da Saúde, que tem entre seus temas prioritários a promoção à cultura da paz e dos direitos humanos. A Política Nacional de Promoção da Saúde (PNPS) propõe: 
Contribuir para a adoção de práticas sociais e de saúde na equidade, na participação e no controle social, a fim de reduzir as desigualdades sistemáticas, injustas e evitáveis, respeitando as diferenças de classe social, de gênero, entre gerações; étnico-raciais, culturais, territoriais; e relacionadas às pessoas com deficiências e necessidades especiais. (BRASIL, 2018, p. 11, grifo nosso).

Uma vez aceitos os profundos impactos que a violência de gênero causa sobre as vítimas, fica evidente a importância de estratégias de seu enfretamento. As medidas de enfrentamento à violência e a proteção das mulheres em tempos de pandemia têm caráter mais imediato, indo desde garantir 0 atendimento dos serviços on-line 24 horas, agilizar a concessão das medidas protetivas, reforçar as campanhas que tenham foco na denúncia de parentes, vizinhos e amigos e incentivo às ações de acolhimento, reforçando o que já vem sendo realizado por instituições governamentais e não governamentais. Além disso, é preciso maior agilidade do julgamento das denúncias de violência doméstica, todas medidas que visam a garantia dos direitos e da saúde da mulher (MARQUES et al., 2020; VIEIRA et al., 2020).

\section{CONCLUSÃO}

Desde muito tempo as mulheres têm as mesmas obrigações que os homens. Urge, portanto, que elas tenham os mesmos direitos. Entre eles, o mais elementar: o direito a uma vida livre de todas as formas de violência. A cultura da paz não pode ser uma palavra vazia a compor um parágrafo utópico da Política Nacional de Promoção da Saúde ou de outros documentos similares.

Quando já se conhecem as consequências da violência de gênero sobre a saúde das mulheres é inadmissível que se fale em promover saúde e qualidade de vida sem uma crítica veemente ao modelo patriarcal de sociedade, que se sustenta na superioridade masculina. A promoção da saúde, entendida como estratégia de empoderamento dos indivíduos, tanto por meio de ações individuais quanto mediante políticas e programas de saúde pública, não pode ser desassociada da equidade de gênero. É importante os governantes, as autoridades de diferentes esferas da sociedade e toda a sociedade civil façam esforços para deslegitimar as masculinidades hegemônicas que naturalizam a violência de gênero, comprometem a saúde e caucionam modos de adoecimento e morte das mulheres.

\section{REFERÊNCIAS}

BARSTED, L. L. O feminismo e o enfrentamento da violência contra as mulheres no Brasil. In: SARDENBERG, C. M. B.; TAVARES, M. S. (org.). Violência de gênero contra mulheres: suas diferentes faces e estratégias de enfrentamento e monitoramento. Salvador: Edufba, 2016. 
BATISTA, K.B.C. et al. Gestores de saúde e o enfrentamento da violência de gênero contra as mulheres: as políticas e sua implementação em São Paulo. Cad. Saúde Publ., v. 34, n. 8, p. e00140017, 2018.

BRASIL. Ministério da Saúde. Secretaria de Vigilância em Saúde, Secretaria de Atenção à Saúde. PNPS - Política Nacional de Promoção da Saúde. Anexo I da Portaria de Consolidação n. 2, de 28 de setembro de 2017. Brasília: MS, 2018.

BUSS, P. M. Promoção da saúde e qualidade de vida. Ciênc. Saúde Col., v. 5, n. 1, p. 163-177, 2000.

G1 - Portal de Notícias. Casos de coronavírus e número de mortos no Brasil, 2020. 8 de junho de 2020. Disponível em https://g1.globo.com/bemestar/coronavirus/noticia/2020/06/08/casos-decoronavirus-e-numero-de-mortes-no-brasil-em-8-de-junho.ghtml. Acesso em: 8 jun. 2020.

GARCIA, L. P. A magnitude invisível da violência contra a mulher. Epidemiol. Serv. Saúde, v. 25, n. 3, p. 451-454, 2016.

HOOKS, B. 0 feminismo é para todo mundo: políticas arrebatadoras. Rio de Janeiro: Rosa dos Tempos, 2019.

IPEA - Instituto de Pesquisa Econômica Aplicada: Fórum Brasileiro de Segurança Pública. Atlas da violência. Brasília: IPEA. 2019.

MARQUES, E. S. et al. A violência contra mulheres, crianças e adolescentes em tempos de pandemia pela COVID-19: panorama, motivações e formas de enfrentamento. Cad. Saúde Públ., Rio de Janeiro, v. 36, n. 4, e00074420, 2020.

MINAYO, M. C. S.; SCHENKER, M. Complexidade da violência e impactos sobre a saúde. In: ASSIS, S. G.; SILVEIRA, L. M. B. (org.). 0 tema da violência no ensino em saúde coletiva: articulações com pesquisa e extensão. Rio de Janeiro: E-Papers, 2018.

NEME, C.; SOBRAL, I. Principais resultados. In: BUENO, S.; LIMA, R.S. (cord.). Visível e invisível: a vitimização de mulheres no Brasil. Brasília: Fórum Brasileiro de Segurança Pública/Instituto Data Folha, 2019.

OMS - Organização Mundial da Saúde. Relatório mundial sobre violência e saúde. Genebra: OMS, 2002.

OPAS - Organização Pan-Americana de Saúde. Folha informativa CoVID-19. Brasil. 6 de maio de 2020. Disponivel em https://www.paho.org/bra/index.php?option=com_content\&view=articleধid=6 101: covid19\&ltemid=875. Aceso em: 6 maio 2020. 
SCOTT, J. Gênero: uma ferramenta útil de análise histórica. Rev. Ed. Real, v. 20, n. 2, p. 91-99, 1985.

VIEIRA, P. R. et al. Isolamento social e o aumento da violência: o que isso nos revela? Artigo Especial. Rev. Bras. Epidemiol., v. 23, e. 200033, 2020.

WHO - World Health Organization. Violence against women: prevalence and health effects of intimate partner violence and non-partner sexual violence. Geneva: World Health Organization, 2013. Disponível em: http://apps.who.int/iris/bitstream/10665/85239/1/9789241564625_eng.pdf. Acesso em: 17 jan. 2020. 
1 Odontólogo, Programa de Pós-Graduação em Promoção da Saúde da Universidade Cesumar; Professor dos cursos de Odontologia e Enfermagem da Universidade Cesumar. E-mail: gustavo.garcia@unicesumar.edu.br

2 Engenheiro Civil, Programa de Pós-Graduação em Promoção da Saúde da Universidade Cesumar.

E-mail: carolineuchallouts@gmail.com

3 Doutor em Fisiologia; Biólogo; Professor do Programa de Pós-graduação em Promoção da Saúde da Universidade Cesumar. E-mail: mbernuci@gmail.com

4 Doutor em História Social; Historiador e Filósofo; Pofessor do Programa de Pós-Graduação em História e Regiões da Universidade Estadual do Centro-Oeste (UNICENTRO. E-mail: sochodolak@gmail.com

5 Doutora em História; Historiadora; Professora do Programa de Pós-Graduação em Promoção da Saúde da Universidade Unicesumar-Maringá-PR.

E-mail: tania.gomes@unicesumar.edu.br

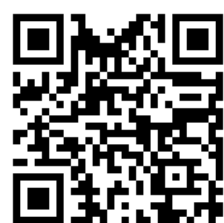

A autenticidade desse artigo pode ser conferida no site https://periodicos. set.edu.br

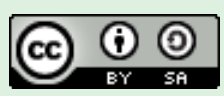

Este artigo é licenciado na modalidade acesso abertosob a Atribuição-Compartilhalgual CC BY-SA

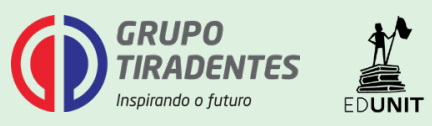

